\title{
Disturbances of cardiac rhythm and conduction in familial amyloidosis with polyneuropathy
}

\author{
PETER ERIKSSON, KJELL KARP, PER BJERLE, BERT-OVE OLOFSSON \\ From the Departments of Internal Medicine and Clinical Physiology, University Hospital, Umea, Sweden
}

SUMMARY Sixteen consecutive patients with familial amyloidosis with polyneuropathy of varying duration and severity underwent 24 hour ambulatory electrocardiographic monitoring. A high incidence of sinus node dysfunction, supraventricular and ventricular arrhythmias, and disturbances of atrioventricular conduction was found. Considerably more arrhythmias and disturbances of conduction were detected by long term electrocardiographic monitoring than by conventional 12 lead electrocardiograms. During a follow up period of three to 14 months five patients needed treatment by a pacemaker, three of them because of symptomatic complete heart block, one because of second degree heart block with heart failure, and one because of symptomatic dysfunction of the sinus node. The tachyarrhythmias did not require specific treatment. Long term electrocardiographic monitoring is a useful adjunct in the evaluation of patients with familial amyloidosis with polyneuropathy as it may detect otherwise unrecognised symptomatic disturbances of heart rhythm. The results may be valid also for other forms of amyloidosis involving the heart.

Familial amyloidosis with polyneuropathy was first described in Portugal in 1952.1 Subsequently, heredofamilial syndromes characterised by systemic accumulation of amyloid with polyneuropathy as a salient feature have been discovered in several other countries, including England, Japan, and the USA. ${ }^{2}$ In Scandinavia, the syndrome has been diagnosed only in the two northernmost counties of Sweden. The first patient was recognised in $1965,{ }^{3}$ and since then about 150 additional cases have been found. The clinical and histopathological findings in familial amyloidosis with polyneuropathy have been described in detail previously. ${ }^{23}$ The heart is involved in the syndrome, ${ }^{4}$ and a high incidence of disturbances of atrioventricular and intraventricular conduction has been reported,,$^{5-7}$ as well as dysfunction of the sinus node. ${ }^{8}$

Previous surveys of disturbances of heart rhythm in all forms of amyloidosis are, however, based solely on conventional 12 lead electrocardiograms. The aim of this study was to assess the occurrence of arrhythmias and disturbances of conduction in a consecutive series of patients with familial amyloidosis with

Requests for reprints to Dr Peter Eriksson, Department of Internal Medicine, University Hospital, S-901 85 Umeå, Sweden.

Accepted for publication 17 January 1984 polyneuropathy by 24 hour ambulatory electrocardiographic monitoring and to evaluate the clinical significance of these electrocardiographic abnormalities.

\section{Patients and methods}

Sixteen consecutive patients with familial amyloidosis with polyneuropathy (six men and 10 women) admitted to this hospital were included in the study. An additional three patients were excluded because they were treated with a pacemaker. Essential data on the patients are given in Table 1 . The mean age of the patients was 53.4 (SEM \pm 2.9 , range 32-69) years and the mean duration of polyneuropathy $8 \cdot 1(\mathrm{SEM} \pm 1 \cdot 3$, range 2-17) years. All patients had a characteristic progressive polyneuropathy, and amyloidosis was found in all of them by histological examination of biopsy specimens from the skin or rectal mucosa. Secondary or myeloma-associated amyloidosis was not found in any of the patients. One patient (case 1) had slight aortic incompetence and one (case 8) slight mitral incompetence. These two together with two additional patients (cases 6 and 14) also had congestive heart failure. None of the patients had a history of recent or previous myocardial infarction or of any other heart disease which might have influenced the results of this study. 
Table 1 Clinical data and routine electrocardiographic findings in 16 patients with familial amyloidosis with polyneuropathy

\begin{tabular}{|c|c|c|c|c|c|c|}
\hline \multirow[t]{2}{*}{ Case No } & \multirow[t]{2}{*}{ Age (yr) } & \multirow[t]{2}{*}{ Sex } & \multicolumn{2}{|c|}{ Polymeuropathy } & \multirow{2}{*}{$\begin{array}{l}\text { Symptoms } \\
\text { attributable to } \\
\text { arrhythmia }\end{array}$} & \multirow[t]{2}{*}{ Routine ECG findings } \\
\hline & & & Duration (yr) & Degree $^{10}$ & & \\
\hline 1 & 67 & $\mathbf{F}$ & 5 & ++ & Dizziness, syncope & $\begin{array}{l}\text { Occasional atrial and ventricular } \\
\text { extrasystoles, second degree AV block } \\
\text { (Mobitz type 1) }\end{array}$ \\
\hline 2 & 49 & $\mathbf{F}$ & 16 & ++++ & Dizziness & LAFB \\
\hline 3 & 67 & $\mathbf{F}$ & 11 & +++ & & Incomplete RBBB \\
\hline 4 & 54 & $\mathbf{F}$ & 8 & ++ & Dizziness & Normal \\
\hline 5 & 68 & $\mathbf{F}$ & 17 & ++ & & Ectopic supraventricular rhythm \\
\hline 6 & 59 & $\mathbf{M}$ & 6 & ++ & Dizziness & $\begin{array}{l}\text { Occasional ventricular extrasystoles, first } \\
\text { degree AV block, LAFB, RBBB }\end{array}$ \\
\hline 7 & 54 & $\mathbf{F}$ & 5 & ++ & Dizziness & First degree AV block \\
\hline 8 & 63 & $\mathbf{F}$ & 10 & +++ & - & Second degree AV block (Mobitz type 1) \\
\hline 9 & 59 & $\mathbf{M}$ & 12 & ++++ & - & Occasional ventricular extrasystoles \\
\hline 10 & 44 & $\mathbf{F}$ & 7 & +++ & Dizziness, syncope & Occasional ventricular extrasystoles \\
\hline 11 & 39 & $\mathbf{M}$ & 2 & + & - & Normal \\
\hline 12 & 42 & $\mathbf{M}$ & 2 & ++ & - & Normal \\
\hline 13 & 48 & $\mathbf{F}$ & 16 & +++ & - & Normal \\
\hline 14 & 69 & $\mathbf{M}$ & 4 & ++ & - & Atrial fibrillation \\
\hline 15 & 32 & $\mathbf{M}$ & 2 & + & - & Normal \\
\hline 16 & 41 & $\mathbf{F}$ & 7 & ++ & Dizziness, syncope & First degree AV block \\
\hline
\end{tabular}

AV, atrioventricular; LAFB, left anterior fascicular block; RBBB, right bundle branch block.

\section{DIAGNOSIS}

The diagnosis of amyloidosis was confirmed by histological examination of biopsy specimens from the skin or rectal mucosa by polarised light after staining with Congo red. ${ }^{9}$ The degree of the progressive polyneuropathy, which in all patients was more pronounced in the legs than in the arms, was graded from slight $(+)$ to very severe $(++++)$ on the basis of the patients' ability to perform routine daily activities. ${ }^{10}$

\section{ELECTROCARDIOGRAPHY}

Twelve lead routine electrocardiograms (I, II, III, aVR, aVL, aVF, and six chest leads) were recorded using a direct writing electrocardiograph (SiemensElema Ltd). Two chest leads were recorded for 24 hours by a two channel electrocardiographic recorder (Oxford Electronic Instruments series 4-24). The leads were positioned so as to achieve optimal $P$ wave visibility and adequate $Q R S$ amplitudes as well as to minimise disturbances. The recordings were checked on an oscilloscope, and the channel with fewest artefacts was replayed, digitised, and stored on a disk memory of a minicomputer (Digital Equipment PDP 11/34).

Analysis of the stored electrocardiogram was carried out by a computer program developed by Nygårds et al. ${ }^{11}$ Visual control by a graphic terminal was undertaken to review abnormalities detected by the automatic analysis. Hence reclassification and corrections of the computer analysis could be performed whenever necessary. All the patients were asked to describe all their routine daily activities and symptoms in a diary during the long term monitoring. The terms and definitions related to cardiac rhythm and conduction followed the recommendations of Hecht et $a l^{12}$ and Robles de Medina et al. ${ }^{13}$

\section{Results}

Seven patients (cases $1,2,4,6,7,10$, and 16) had a history of symptoms attributable to arrhythmias; they had experienced several spells of dizziness, and three of them (cases 1, 10, and 16) had also had syncopal attacks. Two patients reported symptoms related to disturbances of heart rhythm during long term electrocardiographic recording. One patient (case 6) noted palpitation during an attack of ventricular tachycardia and one (case 16) reported dizziness during a period of second degree heart block. Three patients were receiving drugs known to affect cardiac impulse formation and conduction. Thus, one patient (case 6) was being treated with digoxin and two (cases 2 and 12) with carbamazepine because of neuralgia. They were not considered to have received toxic doses of these drugs.

\section{LONG TERM MONITORING}

The results of long term electrocardiographic monitoring are shown in Table 2, and Table 3 summarises the arrhythmias and disturbances of conduction that were found. Sinus rhythm was the basic rhythm in 15 patients and atrial fibrillation in one. In seven patients the heart rate rose above 100 beats $/ \mathrm{min}$, but in no case did it exceed 130 beats/min. Sinus bradycardia below 40 beats/min but above 35 beats/ min occurred in five patients. Two of these and a further two patients had 2-30 sinus pauses lasting 2-2.9 s. Frequent atrial extrasystoles (more than 30 
Table 2 Incidence of arrhythmias and conduction disturbances detected by 24 hour electrocardiographic monitoring in 16 patients with familial amyloidosis with polyneuropathy

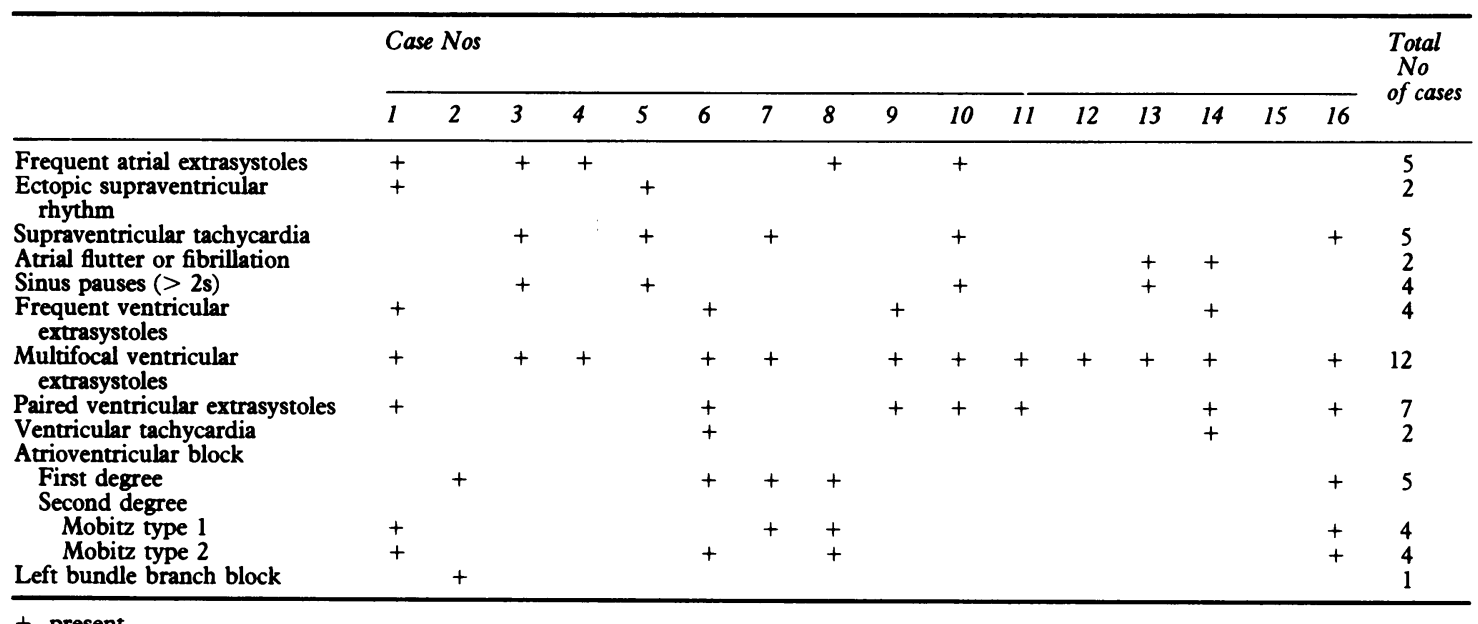

+ , present.

Table 3 Disturbances of cardiac rhythm and conduction detected during 24 hour ambulatory electrocardiographic (ECG) monitoring in 16 patients with familial amyloidosis with polyneuropathy and compared with those found on routine 12 lead electrocardiograms

\begin{tabular}{|c|c|c|}
\hline \multirow[t]{2}{*}{ Finding } & \multicolumn{2}{|c|}{ No (\%) of patients } \\
\hline & $\begin{array}{l}\text { Ambulatory } \\
E C G\end{array}$ & $\begin{array}{l}\text { Routine } \\
\text { ECG }\end{array}$ \\
\hline Sinus pauses $(>2 \mathrm{~s})$ & $4(25)$ & 0 \\
\hline $\begin{array}{l}\text { Supraventricular arrhythmias } \\
\text { Frequent atrial extrasystoles }(>30 / \mathrm{h}) \\
\text { Ectopic supraventricular rhythm } \\
\text { Supraventricular tachycardia } \\
\text { Atrial flutter or fibrillation }\end{array}$ & $\begin{array}{l}10(63) \\
5(31) \\
2(13) \\
5(31) \\
2(13)\end{array}$ & 3 \\
\hline $\begin{array}{l}\text { Ventricular arrhythmias } \\
\text { Frequent ventricular extrasystoles } \\
\text { ( }>30 / \mathrm{h}) \\
\text { Multifocal ventricular extrasystoles } \\
\text { Paired ventricular extrasystoles } \\
\text { Ventricular tachycardia }\end{array}$ & $\begin{array}{r}12(75) \\
4(25) \\
12(75) \\
7(44) \\
2(13)\end{array}$ & 4 \\
\hline $\begin{array}{l}\text { Atrioventricular conduction disturbances } \\
\text { First degree atrioventricular block } \\
\text { Second degree atrioventricular block } \\
\text { (type 1) } \\
\text { Second degree atrioventricular block } \\
\text { (type 2) }\end{array}$ & $\begin{array}{l}\left.\begin{array}{r}6(38) \\
5(31) \\
4(25) \\
4(25)\end{array}\right\}\end{array}$ & $\begin{array}{l}3 \\
2\end{array}$ \\
\hline
\end{tabular}

per hour) were noted in five patients. Six patients had episodes of ectopic supraventricular rhythm or supraventricular tachycardia or both. Paroxysmal atrial flutter was found in one patient. Ventricular extrasystoles were found in 12 patients, and they were frequent (more than 30 per hour) in four. In all patients with ventricular extrasystoles there were two or more ectopic foci. Couplets occurred in seven patients, of whom two had attacks of ventricular tachycardia, each consisting of 3-8 beats.
Intermittent disturbances of atrioventricular conduction were found in six patients. Five patients had first degree block, and in four this was combined with Mobitz type 1 or type 2 second degree block or both. A further patient showed alternating type 1 and type 2 second degree block. Intermittent left bundle branch block was seen in one patient.

\section{ROUTINE MONITORING}

The 12 lead routine electrocardiogram (Table 1) recorded on the day of ambulatory monitoring showed occasional atrial or ventricular extrasystoles or both in four patients. One patient had ectopic supraventricular rhythm and one atrial fibrillation. First degree atrioventricular block was observed in three patients and Mobitz type 1 second degree block in two. Three patients showed disturbances of intraventricular conduction. A comparison between routine 12 lead and long term monitoring (Table 3 ) shows that arrhythmias and disturbances of atrioventricular conduction were observed considerably more frequently by the latter method.

\section{FOLLOW UP}

The patients were followed from 3 to 14 months after ambulatory monitoring. Five patients (cases 2, 6, 8, 10 , and 16) had a pacemaker implanted during this time. Three developed symptomatic complete heart block (cases 2, 6, and 16) despite withdrawal of negative dromotropic drugs (cases 2 and 6). One patient (case 10) developed symptomatic dysfunction of the sinus node. There was prompt relief of dizziness and syncope in these patients after the implantation of a pacemaker. One patient (case 8) had alternating type 1 and type 2 Mobitz second degree atrioventricular 
block and congestive heart failure. She had a pacemaker implanted before abdominal surgery.

\section{Discussion}

We studied 16 patients with familial amyloidosis with polyneuropathy of differing severity at various times after the onset of symptoms. The arrhythmias and disturbances of conduction in our patients far exceeded those found in healthy subjects. ${ }^{14} 15$ Our results also indicate that such disturbances are even more common in this condition than previously reported in surveys of routine electrocardiography. ${ }^{5-7}$ Most important clinically are the disturbances of sinus node function and atrioventricular conduction as these often necessitate treatment by a pacemaker. Supraventricular as well as ventricular arrhythmias were also frequently found. The episodes of tachycardia were, however, usually asymptomatic and not sustained; no specific treatment was required in any of these patients.

In this syndrome serious electrocardiographic abnormalities may develop at any time after the onset of progressive polyneuropathy, except possibly at a very early stage of the disease when the degree of polyneuropathy is slight $(+)$. All patients in this group requiring cardiac pacing had experienced polyneuropathy for five years or more, but we have previously implanted pacemakers in patients with symptoms of this syndrome of only one year's duration. ${ }^{16}$

The heart is involved in all types of systemic amyloidoses, and arrhythmias and disturbances of conduction are common manifestations of such involvement. ${ }^{17} 18$ There are, however, no previous systematic studies of long term electrocardiographic monitoring in any type of amyloidosis. The incidence of serious arrhythmias and disturbances of conduction have probably been underestimated in all forms of amyloidosis. Symptoms such as dizziness and syncope have probably been erroneously ascribed to orthostatic hypotension, a common feature of all types of systemic amyloidosis. ${ }^{19}$ Roberts and Waller recently reported that $15 \%$ of their patients with cardiac amyloidosis died suddenly and unexpectedly, and none of them had congestive heart failure. ${ }^{18}$ This may also be a manifestation of arrhythmias or disturbances of conduction.

The cause of the electrocardiographic abnormalities in amyloidosis is a matter of controversy despite attempts at clinicopathological correlation. Detailed correlative studies of the cardiac conduction system in amyloidosis are few and have produced conflicting results. Some workers favour the hypothesis that infiltration of the conducting system by amyloid is the main reason for the disturbances of conduction, ${ }^{20}$ but others have concluded that direct infiltration by amyloid is of lesser importance. ${ }^{17}$ In familial amyloidosis with polyneuropathy, amyloid infiltration of the sinus node and atrioventricular conduction system is now well documented, and this seems to account for the majority of the electrophysiological disturbances of these regions. ${ }^{2122}$ The distribution and extent of the infiltration of the heart by amyloid are not, however, uniform, and this may account for the widely varying intervals between the onset of the polyneuropathy and clinically significant electrocardiographic abnormalities. Autonomous neuropathy may also contribute to the electrophysiological disturbances and in familial amyloidosis with polyneuropathy amyloid has been found in subepicardial neural tissue. ${ }^{21}$

Drugs affecting impulse formation and conduction-for example, digitalis, antiarrhythmic agents, and also carbamazepine-may aggravate dysfunction of an already compromised conduction system in amyloidosis, and they should be avoided if possible. Sensitivity to digitalis in cardiac amyloidosis has been proposed, 1823 and binding of digoxin by amyloid fibrils was suggested as one possible mechanism for this. ${ }^{23}$

In conclusion, most symptoms attributable to disturbances of cardiac rhythm in familial amyloidosis with polyneuropathy seem to be caused by dysfunction of the sinus node or disturbances of atrioventricular conduction. Tachyarrhythmias are also frequently observed and may also give rise to severe symptoms. Thus long term electrocardiographic monitoring may contribute considerably to the evaluation of symptoms in patients with this condition, and its use could be extended to include all forms of cardiac amyloidosis.

This study was supported by grants from the University of Umea, and the Swedish National Association against Heart and Chest Diseases.

\section{References}

1 Andrade C. A peculiar form of peripheral neuropathy: familiar atypical generalized amyloidosis with special involvement of the peripheral nerves. Brain 1952; 75: 408-27.

2 Glenner GG, Ignaczak TF, Page DL. The inherited systemic amyloidoses and localized amyloid deposits. In: Stanbury JB, Wyngaarden JB, Fredrickson DS, eds. Metabolic basis of inherited diseases. New York: McGraw-Hill, 1978: 1308-39.

3 Andersson R. Familial amyloidosis with polyneuropathy. A clinical study based on patients living in northern Sweden. Acta Med Scand 1976; suppl 590: 1-64. 
4 Hofer P-A, Andersson R. Postmortem findings in familial amyloidosis with polyneuropathy. A study based on six cases from northern Sweden. Acta Pathol Microbiol Scand $[A]$ 1975; 83: 309-22.

5 Olofsson BO, Andersson R, Furberg B. Atrioventricular and intraventricular conduction in familial amyloidosis with polyneuropathy. Acta Med Scand 1980; 208: 77-80.

6 de Freitas AF, Barbedo A. Conduction disturbances in 190 patients with familial amyloidotic polyneuropathy (Andrade's type). Adv Cardiol 1978; 21: 206-9.

7 Sawayama T, Kurihara T, Araki S. Noninvasive cardiovascular findings in familial amyloid polyneuropathy. Br Heart f 1978; 40: 1288-92.

8 Olofsson BO, Eriksson P, Eriksson A. The sick sinus syndrome in familial amyloidosis with polyneuropathy. Int 7 Cardiol 1983; 4: 71-3.

9 Puchtler H, Sweat F, Levine M. On the binding of Congo red by amyloid. $\mathcal{F}$ Histochem Cytochem 1962; 10: 355-64.

10 Olofsson B-O. Pulmonary function in familial amyloidosis with polyneuropathy. Acta Med Scand 1981; 209: 379-84.

11 Nygårds M-E, Ahrén T, Tranesjö J, Wigertz O. A computer program for analysis of long-term ECG recordings. In: Computers in cardiology. Long Beach: IEEE Computer Society, 1979; 429-32.

12 Hecht HH, Kossmann CE, Childers RW, et al. Atrioventricular and intraventricular conduction. Revised nomenclature and concepts. Am $\mathcal{F}$ Cardiol 1973; 31: 232-44.

13 Robles de Medina EO, Bernard R, Coumel P, et al. Definition of terms related to cardiac rhythm. Am Heart f 1978; 95: 796-806.

14 Barrett PA, Peter CT, Swan HJC, Singh BN, Mandel
WJ. The frequency and prognostic significance of electrocardiographic abnormalities in clinically normal individuals. Progr Cardiovasc Dis 1981; 23: $299-319$.

15 Bjerregaard P. Prevalence and variability of cardiac arrhythmias in healthy subjects. In: Chamberlain DA, Kulbertus H, Mogensen L, Schlepper M, eds. Cardiac arrhythmias in the active population; prevalence, significance and management. Mölndal: AB Hässle, 1980; 24-32.

16 Eriksson P, Olofsson BO. Pacemaker treatment in familial amyloidosis with polyneuropathy. PACE 1984 (in press).

17 Ridolfi R̨L, Bulkley BH, Hutchins GM. The conduction system in cardiac amyloidosis. Clinical and pathologic features of 23 patients. Am $\mathcal{F}$ Med 1977; 62: 677-86.

18 Roberts WC, Waller BF. Cardiac amyloidosis causing cardiac dysfunction: Analysis of 54 necropsy patients. Am $\mathcal{F}$ Cardiol 1983; 52: 137-46.

19 Kyle RA, Bayrd ED. Amyloidosis: Review of 236 cases. Medicine (Baltimore) 1975; 54: 271-99.

20 James TN. Pathology of the cardiac conduction system in amyloidosis. Ann Intern Med 1966; 65: 28-36.

21 Eriksson A, Eriksson P, Olofsson B-O, Thornell L-E. The cardiac atrioventricular conduction system in familial amyloidosis with polyneuropathy. A clinicopathologic study of six cases from northern Sweden. Acta Pathol Microbiol Immunol Scand [A] 1983; 91: 343-9.

22 Eriksson A, Eriksson P, Olofsson B-O, Thornell L-E. The sinoatrial node in familial amyloidosis with polyneuropathy. A clinico-pathological study of nine cases from northern Sweden. Virchows Arch (Pathol Anat) 1984; 402: 239-46.

23 Rubinow A, Skinner M, Cohen AS. Digoxin sensitivity in amyloid cardiomyopathy. Circulation 1981; 63: 12858. 